\title{
THE AUSTRALIAN COASTAL OCEAN RADAR NETWORK FACHITY
}

\author{
M.L.Heron
}

\author{
Australian Coastal Ocean Radar Network \\ Marine Geophysical Laboratory \\ James Cook University \\ Townsville, Australia
}

\begin{abstract}
The Australian Coastal Ocean radar Network (ACORN) is a monitoring network of HF radars which are being installed around Australia under a National Collaborative Research Infrastructure Strategy (NCRIS). It is a five-year project, at the end of which there will be five pairs of radar stations and one triplet installed and operating, enabled by the central pool of funding for the Integrated Marine Observing System (IMOS) which is a part of NCRIS, and augmented by funding from other sources. At each chosen site there is a pair (or triplet) of radar stations, mounted on the shore, which receive radar echoes from the rough sea. Four of the pairs of radar stations are phased array installations and one pair and the triplet are of the amplitude direction finding genre. The NCRIS strategy is to provide easily accessed data, freely available to researchers in quality controlled archives. The IMOS aim is to produce data which will support research into coastal dynamics and exchange between the open ocean and the continental shelf. In addition to research in coastal oceanography, the data are available for algorithm development and evaluation of new applications for HF ocean radar. There is potential for application of the data to management of coastal marine resources, and in marine safety areas. Real-time maps of surface currents and the prospect of short-term forecasting have the potential to reduce search areas in coastal waters and to make pollution/spill mitigation more effective. With the establishment of HF radar monitoring stations like those in ACORN, there is growing opportunity for researchers around the world to access data from well curated archives to carry out basic research on physical oceanography, or applications research without having direct access to the measuring facility. This feature brings the ACORN HF radars into GEOSS for coastal processes and dynamics.
\end{abstract}

Index Terms - HF Radar; Surface Currents; Data Archives; Coastal Oceans.

\section{NCRIS/IMOS/ACORN: STRUCTURE AND GOALS}

The Australian Federal Department of Science, Industry, Innovation and Research has established a National Collaborative Research Infrastructure Strategy (NCRIS) to encourage the organization of research data into properly curated archives which are easily and freely available to researchers. NCRIS covers a wide range of basic research, and one of its ten major capabilities is the Integrated Marine Observing System (IMOS). IMOS was formed through a grass-roots process in which the Australian marine research community were asked to contribute their vision of the types of ocean observations which should go into such an archive.

\section{THE AUSTRALIAN COASTAL OCEAN RADAR NETWORK (ACORN)}

The core of the Australian Coastal Ocean Radar Network (ACORN) consists of three HF radar pairs and one triplet, which are being deployed at various points around the Australian coastline. ACORN includes phased array, beam-forming technology as well as the small footprint, amplitude direction-finding technology, in order to offer maximum flexibility in site selection, and availability of a wide range of monitored parameters. Two additional HF radar systems are being acquired by funds outside the IMOS capital budget and are managed by ACORN in return for the data being delivered to the IMOS archive. One of these is in the Great Barrier Reef Lagoon and one is in South Australia at the entrance to the Spencer Gulf and the Gulf of St Vincent. The sites for the first series of deployments (three pairs and one triplet) are shown in Fig. 1 as red stars, and the yellow stars show the locations of the last two sites in the ACORN programme. The first approved installations are around Heron Island in the Capricorn and Bunker Groups on the Great Barrier Reef, west of Kangaroo Island in the Southern Ocean, and the north side of Perth in the Indian Ocean. 


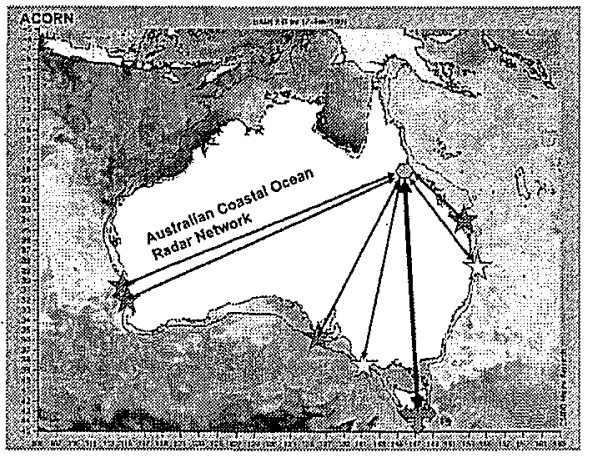

Figure 1. Initial deployments of three pairs and one triplet HF radar systems. The field sites are marked with red stars, the location of the data and maintenance laboratory is green and the IMOS archive centre has the purple cross. The yellow stars mark the positions of the final two station pairs. The background sea surface temperature map is a product from CMAR's BLUELINK computer model [1].

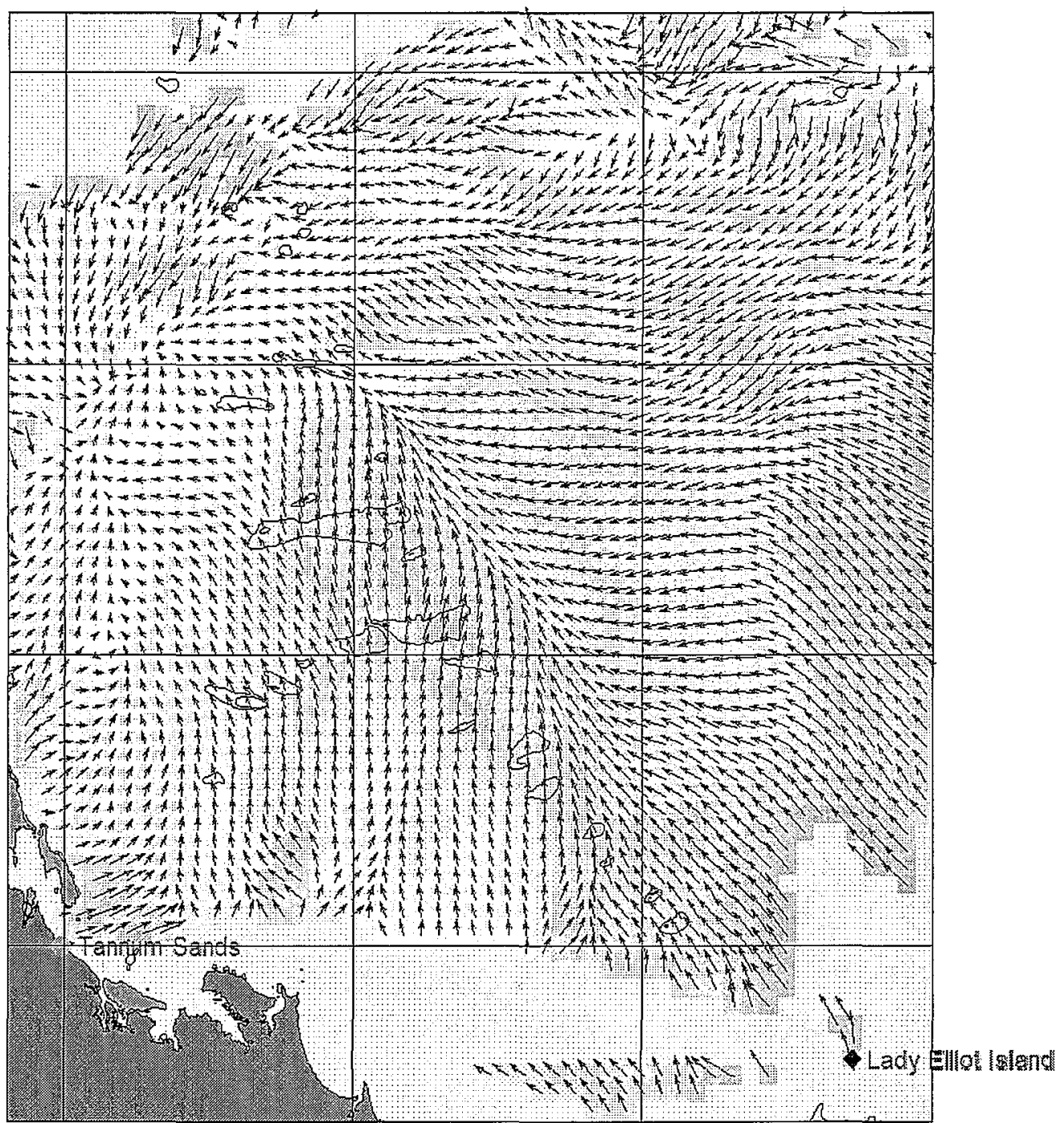

Figure 2. A 10-minute grab of surface current data from the GBR radar system. The data points are not smoothed in time or space, and are untouched data from the real-time processor. The marked grid lines are spaced $50 \mathrm{~km}$ apart. The arrows are surface current vectors, typically up to $20 \mathrm{~cm} / \mathrm{s}$. 


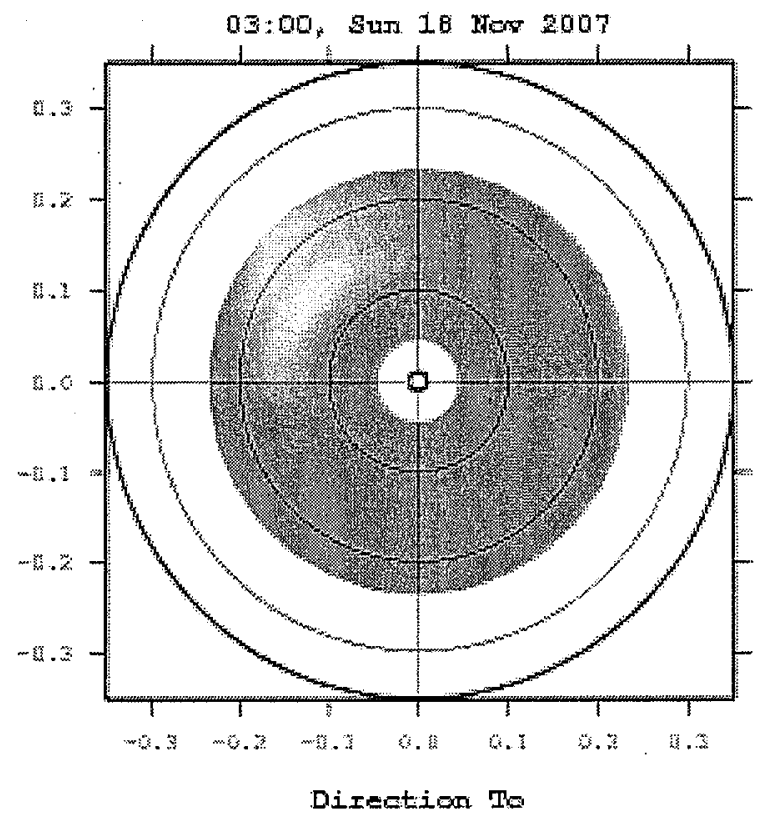

Figure 3. Directional wave spectrum showing the dominant energy towards the north-west at a wave period of about $0.17 \mathrm{~s}$, and a secondary peak shifted about 10 degrees to the north with a dominant wave period of about $0.2 \mathrm{~s}$.

Directional wave spectra are taken from a group of $4 \times 4$ pixels and integration over a period of 1 hour.

The data will be routed through a central laboratory for quality assurance and metadata labelling. System diagnostic data will also be sent to the central laboratory and all monitoring and maintenance will originate there. The maintenance model is a combination of caretaker casual staff at each site, with full technical competence at the central laboratory. The main advantage of this centralised model is that it will ensure that the data are archived in a consistent way. There is a need to build capacity and expertise around the country, and discussion is underway to determine the relative emphasis which should be placed on technical expertise and on applications expertise, and science. Deployment of the radars will be in support of IMOS regional nodes where there is a range of identified questions concerned with boundary currents and associated eddies and their interactions with shelf water and topography. In turn these are linked to productivity, connectivity of biological populations and phenomena such as coral bleaching and diseases. In most cases the use of HF radars will be complemented by data from regional moorings and by the fleet of unmanned gliders. The radar network will provide a basis for applied research in wave prediction and will offer test sites for hydrodynamic modelling.

\section{HF RADAR: THE SEA SURFACE PARAMETERS THAT IT PRODUCES}

The main product from the HF radar is the map of surface currents. With the configuration at the GBR site we produce a map of surface currents every 10 minutes on a $4 \mathrm{x}$ $4 \mathrm{~km}$ grid over an area of about $150 \mathrm{~km} \mathrm{x} 150 \mathrm{~km}$. One such 10-minute grab is shown in Fig. 2 for the GBR radar system. These surface current maps are archived with quality assurance indices on each data point. Surface current components are measured as radial components along the line from the grid point to the radar station and are derived from the frequency of the first-order peaks in the Doppler spectrum of radar echoes. Because it is based on a frequency standard, the precision of these data is generally very good. Significant wave heights and wind directions are also produced every 10 minutes on the same grid. Significant wave heights are derived from the ratio of energy in the second-order continuum in the Doppler spectra of radar echoes, to the energy in the adjacent first-order spectral line. The algorithm relating this ratio to the significant wave height involves empirical analysis and the use of a semi-empirical model (Graber and Heron, 1997 [2]; Heron and Heron, 1998 [3]). For this reason significant wave height data are less robust than surface current data. Wind direction is derived from the ratio of energy in the two first-order spectral lines. The algorithm to derive wind direction requires data from both radar stations and involves adoption of a model for the directional pattern of wind waves generated by the steady wind (Heron and Prytz, 2002 [4]; Heron, 2005 [5]). Like significant wave height, this is not a robust measurement and errors are likely to be above $10 \%$ or 10 degrees, whichever is the larger. Directional wave spectra are produced for a reduced spatial grid and at hourly intervals. This is because we need to average over space and time to improve the signal-to-noise ratio in the Doppler spectra before the directional wave spectra are calculated (Wyatt et al., 2006 [6]; Wyatt et al., 2008 [7]). A typical directional wave spectrum produced from the GBR radar system is shown in Fig. 3.

\section{CONCLUSION}

The Australian Coastal Ocean Radar Network is being established as a development of research infrastructure in Australian coastal waters. The sites have been chosen because of research challenges in those areas, and generally they are associated with the deployment of other equipment like acoustic current profilers and wave measuring buoys. The data are archived centrally in a way that is easily accessed and essentially free for research use. Some research and operational applications are restricted to the specific sites of the deployments, but there are many research challenges of a more general nature which can be 
addressed using these data, but which apply globally to other locations. Some of the potential research is of a fundamental nature and not connected with any specific measuring site.

With large data archives like this, and other IOOS archives, there are increasing opportunities for researchers to participate in research projects without the need to own expensive equipment items.

\section{ACKNOWLEDGEMENTS}

Figure 1 is a typical output product from the BLUElink Operational Model. This work is supported by the Australian Research Council with grant LE0560892. It is a product of the Australian Coastal Ocean Radar Network, the Integrated Marine Observing System, and the Australian National Collaborative Research Infrastructure Strategy.

\section{REFERENCES}

[1] www.cmar.CSIRO.au/BLUElink.

[2] Graber, H.C., and M.L.Heron, (1997) Wave height measurements from HF radar, Oceanography, 10, 90-92.
[3] Heron, S.F. and M.L.Heron (1998), A comparison of algorithms for extracting significant wave height from $\mathrm{HF}$ radar ocean backscatter spectra, J. Ocean and Atmos. Technology, 15, 1157-1163.

[4] Heron,M.L. and A:Prytz; (2002); Wave height and wind direction from the HF coastal ocean: surface radar, Canadian J. Remote Sensing, 28; 385-393:;

[5] Heron,M.L., (2005), The role of HF ocean surface radar in Australia as a long-term coastal ocean monitoring facility, IEAust. Coasts and Ports, CDROM.

[6] Wyatt,L.R., J.J.Green, A.Middleditch, M.D.Moorhead, J.Howarth, M.Holt and S.Keogh, (2006), Operational wave, current and wind measurements with the Pisces HF radar, IEEE J.Oceanic Eng., 31, 819-834.

[7] Wyatt,L.R., J.J.Green and A.Middleditch, (2008), Signal sampling impacts on HF radar wave measurement, J. Atmospheric and Oceanic Technology, in press. 